\title{
Assessing the impact of the 2008 health reform in Ecuador on the performance of primary health care services: an interrupted time series analysis
}

Sergio E Flores Jimenez and Miguel San Sebastián ${ }^{*}$

\begin{abstract}
Background: In 2008, Ecuador started a national health reform based on the principles of Alma Ata to achieve Universal Health Coverage. While coverage indicators have increased, a systematic assessment of the impact of the reform on the delivery of health services at primary level is lacking. The aim of this study was to assess the impact of the 2008 health reform on the performance of primary health care services in Ecuador.

Methods: Ambulatory Care Sensitive Conditions (ACSC) are a subset of diseases where hospital admission is potentially avoidable by high quality well-functioning primary care. Thus, observing the behaviour of ACSC hospitalizations can serve as an indicator of how the primary health care level is performing. Crude and adjusted rates, stratified by sex, were calculated from ten selected ACSC hospitalization discharges during 22 years of data representing 11 years before and after the health reform. An interrupted time series analysis was then conducted by applying a negative binomial regression and adjusting for overdispersion and autocorrelation.

Results: Overall higher crude and adjusted rates for ACSC hospitalizations were observed in women compared to men; both increased gradually since the start of the observation, reaching a peak around 2010, and then started a downwards trend. In men, the incidence rate ratio increased significantly by $3 \%$ per year during the period before the intervention. During the first year after intervention, an increase (13\%) was detected, and then a statistically significant $1 \%$ decrease $(\mathrm{IRR}=0.99 ; 95 \% \mathrm{Cl}$ : 0.98, 0.99) was observed in the ACSC rate ratio per year in the period after the intervention. Similar trends and effect sizes were found for women.

Conclusions: The study revealed significant decreasing trends of the ACSC hospitalization rates in both sexes, indicating an improvement of the performance of the primary health care services following the 2008 national health reform. A continuous strengthening of the primary care model as well as a regular monitoring of ACSC hospitalization rates in the country is recommended. A health economic evaluation considering hospitalizations avoided and associated costs is also advisable.
\end{abstract}

Keywords: Ambulatory care sensitive conditions, interrupted time series analysis, primary health care, health reform, Ecuador

\footnotetext{
* Correspondence: miguel.san.sebastian@umu.se

Department of Epidemiology and Global Health, Umeå University, Umeå,

Sweden
}

C C The Author(s). 2021 Open Access This article is licensed under a Creative Commons Attribution 4.0 International License, which permits use, sharing, adaptation, distribution and reproduction in any medium or format, as long as you give appropriate credit to the original author(s) and the source, provide a link to the Creative Commons licence, and indicate if changes were made. The images or other third party material in this article are included in the article's Creative Commons licence, unless indicated otherwise in a credit line to the material. If material is not included in the article's Creative Commons licence and your intended use is not permitted by statutory regulation or exceeds the permitted use, you will need to obtain permission directly from the copyright holder. To view a copy of this licence, visit http://creativecommons.org/licenses/by/4.0/ The Creative Commons Public Domain Dedication waiver (http://creativecommons.org/publicdomain/zero/1.0/) applies to the data made available in this article, unless otherwise stated in a credit line to the data. 


\section{Background}

Many countries throughout the world have recently framed their national health policies towards the goal of achieving Universal Healthcare Coverage (UHC) [1]. This strategy advocates quality health care services accessible to all people according to need, as well as financial protection to avoid users' economic hardship. In order to achieve UHC, the World Health Organization has suggested the need to raise funds from taxes, to reduce the reliance on direct payments to finance services, and to improve efficiency and equity under a framework that organizes and delivers care that best meets the population needs [2].

Starting in the $2000 \mathrm{~s}$, UHC has been prominent in the political agendas of many Latin American countries based on comprehensive primary health care (PHC) models [3]. All countries in this region have committed to the implementation of UHC through its inclusion in their policy documents. These countries are also making efforts to reform their health financing to increase the pooling of funds, guaranteeing access to an essential package of services and providing financial protection to the most vulnerable [4]. Consequently, several countries have reorganized their health systems to address structural fragmentation, decentralize health system functions to local levels of government, develop robust regulatory functions, and separate purchasing and provider roles [5]. An article from 2015 assessed the progress towards UHC using data from 112 household surveys in 20 Latin American countries between 1990 and 2013 monitoring several indicators of health service coverage (antenatal visits, full immunization for children, breast and cervical cancer screening), treatment coverage (skilled birth attendant, appropriate treatment for children's diarrhea and respiratory infection) and financial protection (catastrophic out-of-pocket and impoverishing spending on health care services). The review concluded that all countries were moving in the right direction but were still far from achieving full UHC [6].

One of the countries which has undertaken important structural changes in both the constitutional reform of the right to health and the organization of public institutions has been Ecuador [7]. In 2008 the constitution was reformed to make health care a right [8]; it sought to build a new health care model that was not centred around diseases and curative health services, but on people, family, and community, with a strong perspective of health promotion, prevention, and rehabilitation. The model, built on the principles of Alma Ata, started by offering free cost health services to the entire population, which increased the utilization of healthcare services by $300 \%$ during the period between 2008 and 2016. In addition to a strong investment in health infrastructure, the country increased the salaries of the health workforce and recruited more than 5,000 health professionals between 2012 and 2015 [9].

Two studies have assessed the role of the Ecuadorian health reform on decreasing socioeconomic inequalities in health care utilization and health outcomes, respectively $[10,11]$. In the first one, a decrease in income inequalities in curative visits was observed after the reform. The second study revealed a more complex picture where most socioeconomic inequalities in skilled birth attendance, but not in cervical cancer screening or the use of modern contraceptives, had decreased during the reform period.

However, except by information related to coverage indicators [9], no study has systematically assessed the impact of the reform on the functioning of health services at the primary level. The aim of this study was to assess the impact of the 2008 health reform on the performance of primary health care services in Ecuador.

\section{Methods \\ Design and data source}

Ambulatory Care Sensitive Conditions (ACSC) are a subset of diseases where hospital admission is potentially avoidable by preventing the onset of disease, controlling an acute episodic illness, or managing a chronic condition effectively by providers at primary care level. With high quality well-functioning primary care, the need for hospital care for these conditions should be reduced [12, 13]. Therefore, observational evidence on the behaviour of ACSC hospitalizations can serve as an indirect indicator of how a primary health care system is performing. This approach has been previously used in the Latin American region [14-17].

To evaluate the effectiveness of the 2008 health reform in Ecuador through its impact on the changes of ACSC, a quasi-experimental study design was undertaken using an interrupted time series analysis (ITSA). This design is commonly used to assess the consequences of a variety of policy issues in various fields, such as community interventions, public policy, regulatory actions, environmental policies, financial economics, health technology assessment, and health policies [18]. It is particularly suited to evaluate public health interventions introduced at the population level over a clearly defined period of time $[19,20]$.

Ten ACSC covering 22 years of data spanning 11 years before and after the health reform were selected. The ACSC included gastroenteritis, diabetes, diarrhoea, angina, heart failure, pneumonia, chronic obstructive pulmonary disease, asthma, cellulitis, and urinary tract infections. They were chosen based on previous studies conducted in Ecuador [14, 15] and retrieved following their respective International Classification of Diseases (ICD-9/10) codes. 
The total number of national hospital discharges - including both conditions identified as ACSC and nonACSC - aggregated by year (1997-2018), sex, and age was extracted from the National Institute of Statistics and Census (INEC in Spanish) database of Ecuador. This information is publicly available at: https://www. ecuadorencifras.gob.ec/camas-y-egresos-hospitalarios/. National populations per age brackets and sex were obtained for every year using the same source. The world standardized population for each age bracket was obtained from the World Health Organization (WHO) [21]. All this data was inserted into an Excel file and then transferred into a Stata database.

\section{Data analysis}

The crude rate per 1000 people was calculated based on the number of ACSC reported per year and the population for each respective age bracket; the age adjusted ACSC rate was calculated through the direct standardization method using the WHO standard population as a reference. The crude and adjusted rates were then plotted into a multiple overlaid connected line graph. Raw data are provided as supplementary material (Table 1S).

Since the outcome was a count, a Poisson regression model was first used including the total population as the denominator to convert the outcome into a rate and adjust for any potential changes in the population over time. The log of the expected outcome was predicted with a linear combination of the predictors:

$\ln (\{\operatorname{acsc}\})=\beta$ o (Intercept $)+\beta 1$ preslope $+\beta 2$ intervention $+\beta 3$ postslope $+\varepsilon t$.

Initial analysis suggested a moderate degree of overdispersion, so a more flexible negative binomial model was used for all analyses. Robust standard errors using the Huber-White sandwich estimator to control for mild violations of underlying assumptions (normality, heteroscedasticity, or large residuals) were calculated. Rate ratios (RR) and $95 \%$ confidence intervals (95\% CI) were obtained as measures of association. As a complementary analysis, total hospitalization rates in both sexes over the same period were also calculated (Fig. $1 \mathrm{~S}$ in the Additional file 1). All statistical analyses were conducted using Stata 16.1.

\section{Ethical approval}

All the data obtained are publicly available online and provided by the government's national agency of statistics in an aggregated format. No specific ethical procedures had to be undertaken regarding data collection or anonymity.

\section{Results}

In total, 2,245,339 (11.02\% of the total) ACSC hospitalizations were included in the period 1997-2018 (supplementary Table 2S). Overall higher crude and adjusted rates for ACSC hospitalizations were observed in women compared to men, both increasing gradually since the start of the observation, reaching a peak around 2010 and then starting a downwards trend (Fig. 1). In men, the incidence rate ratio increased significantly by $3 \%$ per year during the period before the intervention. During the first year after intervention, an increase $(13 \%)$ was detected, followed by a statistically significant $1 \%$ decrease (IRR $=0.99 ; 95 \% \mathrm{CI}$ : 0.98, 0.99) in the ACSC rate ratio per year in the period after the intervention. Similar trends and effect sizes were found for women (Table 1).

When calculating the pre- and post-trend difference, a statistically significant $5 \%$ decrease (IRR $=0.95 ; 95 \% \mathrm{CI}$ : $0.94,0.96)$ in the ACSC rate ratio was observed in both sexes (Fig. 2; Table 1).

\section{Discussion}

This study assessed the performance of primary health care services, measured by the ACSC, after the implementation of a national health reform in Ecuador. The findings have revealed that the health reform seemed to have attained a positive effect on improving the performance of the health care system. These results expand a previous study describing ACSC trends in Ecuador in the period 2002-2012, where no intent to relate the trends with the 2008 health reform was performed [14]. Our results are in line with an Inter-American Development Bank report on ACSC in selected countries of the Latin American region using data ranging from 2001 to 2009 (15). While the report found an average percentage of ACSC for all hospitalizations ranging between $10.8 \%$ (in Costa Rica) and $21.6 \%$ (in Colombia), our average percentage for the study period was $15.1 \%$ for men and $10.1 \%$ for women.

The main finding of this study was the significant decrease in the trend of ACSC hospitalization rates for both men and women after the reform started in 2008. The pattern of increasing trends immediately following the intervention may be due to the refractory period between legislation and implementation. A health care reform, from legislative approval to institutional implementation, requires time to be set in place, let alone to start seeing its effects. This is especially relevant in this case considering the national scale and complexity of the intervention.

Despite the decrease in rates of ACSC after the reform, they were still higher than in the $90 \mathrm{~s}$ before any reform was implemented. One explanation of this apparently contradictory situation could be that overall hospitalization rates were low in the $1990 \mathrm{~s}$ due to a lack of access to these facilities. This was observed when further analyses were conducted that examined total hospitalization rates in both sexes over the same period (see Fig. $1 \mathrm{~S}$ in the Appendix). Hospitalization rates were 

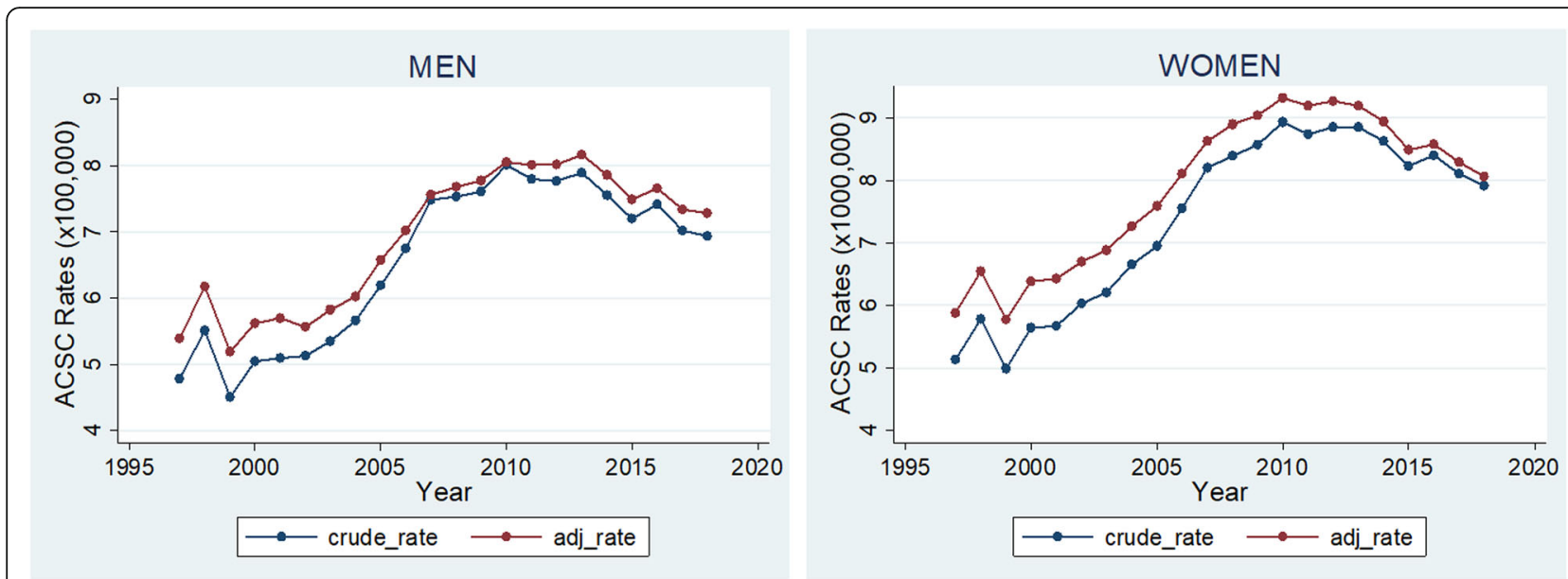

Fig. 1 Trends in crude and age-adjusted ambulatory care sensitive conditions ACSC rates (x 100,000) by sex, 1997-2018, Ecuador

low during the $1990 \mathrm{~s}$ and beginning of the $2000 \mathrm{~s}$ increasing significantly after the health reform.

The positive impact of the reform on primary health care services is consistent with studies conducted in the region. In the $1990 \mathrm{~s}$, Brazil introduced the Family Health Program (Programa de Salud Familia), which developed a new, more robust model of primary health care services designed to provide accessible, first contact, comprehensive, and whole person-centred care [22]. Different studies carried out in 2008, 2009, and 2011 found that overall hospitalization rates due to ACSC significantly decreased with varying degrees between both sexes $[16,17,22]$.

To our knowledge, there has not been conducted a comprehensive evaluation of the health reform in Ecuador. While different stakeholders linked to the reform implementation have advocated its success $[9,23]$, other scholars have claimed that the reform has been insufficient. Except for the higher budget allocated, limited changes have been implemented in the structure of the health system [24, 25] which could explain the slow decreasing pattern of ACSC post-reform observed.

Table 1 Segmented negative binomial regression analysis including incidence rate ratios (IRR) and their $95 \%$ confidence intervals (95 \% Cl); pre- and post-intervention by sex, 1997-2018, Ecuador

\begin{tabular}{lllllll}
\hline & \multicolumn{3}{c}{ Men } & & & \multicolumn{2}{l}{ Women } \\
\cline { 2 - 3 } & IRR & $\mathbf{( 9 5 \% ~ C l )}$ & & IRR & $\mathbf{( 9 5 \% ~ C l )}$ \\
\hline Pre-intervention slope & 1.03 & $(1.02-1.04)^{*}$ & & 1.04 & $(1.03-1.05)^{*}$ \\
Intervention & 1.13 & $(1.05-1.21)^{*}$ & & 1.11 & $(1.05-1.17)^{*}$ \\
Post-intervention slope & 0.99 & $(0.98-1.00)$ & 0.99 & $(0.98-0.99)^{*}$ \\
Pre- post trend difference & 0.95 & $(0.95-0.97)^{*}$ & & 0.95 & $(0.94-0.96)^{*}$ \\
\hline
\end{tabular}

${ }^{*} p<0.05$

\section{Methodological considerations}

Several issues should be considered when interpreting these findings. Interrupted time series analysis has been considered as one of the strongest quasi-experimental research designs, particularly when a randomized trial is unfeasible or unethical $[18,19]$. The availability of longitudinal population rates spanning eleven years before and after the health reform policy can be considered enough to capture the differences in hospitalization rates and therefore the effects of the intervention. While there is a strong assumption in the design that the reform is the cause of the outcomes, it was not possible to rule out other potential confounders that could affect the prevalence of the diseases and the visits to health centres and hospitals.

It is important to keep in mind that ACSC are a proxy indicator of the performance of primary health services; while commonly accepted in the literature $[13,15]$, there might other, more direct measures of performance that were not possible to apply in this study. The diseases selected to obtain the ACSC were based on previous studies from the region and covered all age groups; however, attention should be paid when making comparison with studies that included other type of diseases and/or agespecific conditions. While case ascertainment and reporting can be an issue, it was not possible to assess the quality of the register used.

\section{Conclusion}

The study revealed an important change in the pattern of ACSC hospitalization rates, from an increasing trend since the beginning of the $1990 \mathrm{~s}$, peaking around the time of the intervention, to a decreasing trend following the 2008 constitutional health reform. A very similar pattern both in magnitude and direction of the ACSC rates was observed in both sexes. Given that the 

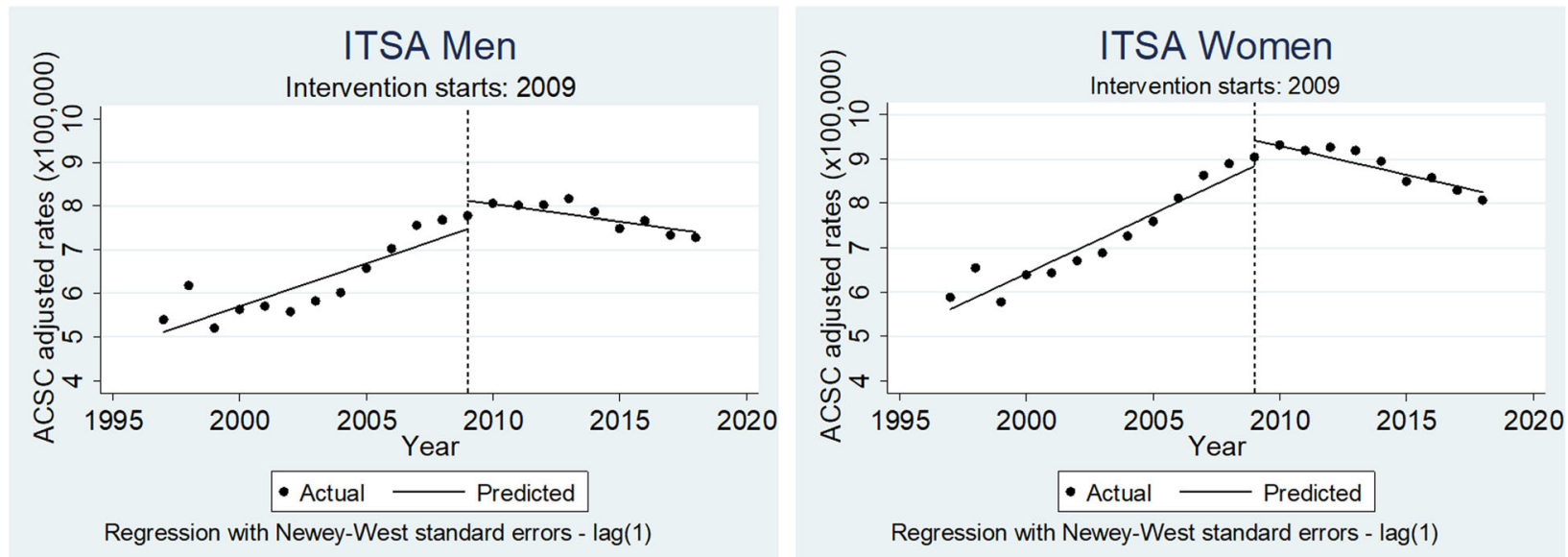

Fig. 2 Trends in ambulatory care sensitive conditions (ACSC) age-adjusted rates (per 100,000 population) with fitted regression line before (19962008) and after (2009-2018) the health reform in Ecuador in men (left) and women (right); (ITSA=interrupted time series analysis)

implemented health care reform seems to improve the performance of primary care services, a continuous strengthening of the primary care model in the country is recommended. Additionally, a regular monitoring of ACSC hospitalization rates in the coming years is advisable to ascertain whether the effects of the intervention are long lasting and sustainable. Finally, a health economic evaluation considering avoided hospitalizations and associated costs is suggested to allow a broader discussion of the sustainability of this primary health care model.

\section{Supplementary Information}

The online version contains supplementary material available at https://doi. org/10.1186/s12939-021-01495-2

Additional file 1.

Additional file 2.

Additional file 3.

\section{Acknowledgements}

None.

\section{Authors' contributions}

Miguel San Sebastian came out with the idea; Sergio Flores analyzed the data, led the interpretation of the results and drafted the manuscript with support of Miguel San Sebastian. All authors have read and approved the final manuscript.

\section{Funding}

This study was partly funded by the Swedish Institute Scholarship. Open Access funding provided by Umea University.

\section{Availability of data and materials}

The data that support the findings of this study are publicly available at: https://www.ecuadorencifras.gob.ec/camas-y-egresos-hospitalarios/.

\section{Declarations}

Ethics approval and consent to participate Not applicable.

\section{Consent for publication}

Not applicable.

\section{Competing interests}

The authors declare that they have no competing interests.

Received: 29 January 2021 Accepted: 9 June 2021

Published online: 22 July 2021

\section{References}

1. Reich MR, Harris J, Ikegami N, Maeda A, Cashin C, Araujo EC, et al. Moving towards universal health coverage: lessons from 11 country studies. Lancet. 2016;387(10020):811-6.

2. World Health Organization, Etienne C, Asamoa-Baah A, Evans DB, editors. The World health report: health systems financing: the path to universal coverage. Geneva: World Health Organization; 2010. 96.

3. Labonté R, Pooyak S, Baum F, Schaay N, Packer C, Laplante D, et al. Implementation, Effectiveness and Political Context of Comprehensive Primary Health Care: Preliminary Findings of a Global Literature Review. Aust J Prim Health. 2008;14(3):58.

4. Fagan T, Dutta A, Rosen J, Olivetti A, Klein K. Family Planning in the Context of Latin America's Universal Health Coverage Agenda. Glob Health Sci Pract. 2017:5(3):382-98.

5. Atun R, de Andrade LOM, Almeida G, Cotlear D, Dmytraczenko T, Frenz P, et al. Health-system reform and universal health coverage in Latin America. The Lancet. 2015;385(9974):1230-47.

6. Wagstaff A, Dmytraczenko T, Almeida G, Buisman L, Hoang-Vu Eozenou P, Bredenkamp C, et al. Assessing Latin America's Progress Toward Achieving Universal Health Coverage. Health Aff (Millwood). 2015;34(10):1704-12.

7. Pan American Health Organization. Health Systems Profile - Ecuador. 2008. 2008;68.

8. Aldulaimi S, Mora FE. A Primary Care System to Improve Health Care Efficiency: Lessons from Ecuador. J Am Board Fam Med. 2017;30(3):380-3.

9. Espinosa V, Acuña C, de la Torre D, Tambini G. La reforma en salud del Ecuador. Rev Panam Salud Pública. 2017:15:1.

10. Granda ML, Jimenez WG. The evolution of socioeconomic health inequalities in Ecuador during a public health system reform (2006-2014). Int J Equity Health. 2019;18(1):31

11. Quizhpe E, Sebastian MS, Teran E, Pulkki-Brännström A-M. Socioeconomic inequalities in women's access to health care: has Ecuadorian health reform been successful? Int J Equity Health. $2020 ; 19(1): 178$.

12. Busby J, Purdy S, Hollingworth W. A systematic review of the magnitude and cause of geographic variation in unplanned hospital admission rates and length of stay for ambulatory care sensitive conditions. BMC Health Serv Res. 2015;15(1):324.

13. Vuik SI, Fontana G, Mayer E, Darzi A. Do hospitalisations for ambulatory care sensitive conditions reflect low access to primary care? An observational 
cohort study of primary care usage prior to hospitalisation. BMJ Open. 2017; 7(8):e015704.

14. Trujillo H, Carolina M. Comportamiento de las hospitalizaciones evitables por condiciones sensibles a atención primaria en Ecuador, en el período 2002-2012 y sus implicaciones para el fortalecimiento de la medicina familiar. 2014 [cited 2020 Apr 26]; Available from: http://repositorio.puce. edu.ec:80/xmlui/handle/22000/10833.

15. Series of Avoidable Hospitalizations and Strengthening Primary Health Care. Primary Care Effectiveness and the Extent of Avoidable Hospitalizations in Latin America | Publications. [cited 2020 Apr 26]. Available from: https:/publications. iadb.org/publications/english/document/Series-of-Avoidable-Hospitalizations-a nd-Strengthening-Primary-Health-Care-Primary-Care-Effectiveness-and-theExtent-of-Avoidable-Hospitalizations-in-Latin-America.pdf.

16. Guanais F, Macinko J. Primary Care and Avoidable Hospitalizations: Evidence From Brazil. J Ambulatory Care Manage. 2009;32(2):115-22.

17. Nedel FB, Facchini LA, Martín-Mateo M, Vieira LAS, Thumé E. Family Health Program and ambulatory care-sensitive conditions in Southern Brazil. Rev Saúde Pública. 2008;42:1041-52.

18. Lagarde M. How to do (or not to do)... Assessing the impact of a policy change with routine longitudinal data. Health Policy Plan. 2012;27(1):76-83.

19. San Sebastián M, Mosquera PA, Gustafsson PE. Do cardiovascular disease prevention programs in northern Sweden impact on population health? An interrupted time series analysis. BMC Public Health. 2019 Dec;19(1):202.

20. Lopez Bernal J, Cummins S, Gasparrini A. Interrupted time series regression for the evaluation of public health interventions: a tutorial. Int J Epidemiol. 2016; dyw098.

21. Ahmad OB \& Boschi Pinto, Cynthia \& Lopez, A.D. (2001). Age Standardization of Rates: A New WHO Standard. GPE Discussion Paper Series: No 31. 10-12.

22. Dourado I, Oliveira VB, Aquino R, Bonolo P, Lima-Costa MF, Medina MG, et al. Trends in Primary Health Care-sensitive Conditions in Brazil: The Role of the Family Health Program (Project ICSAP-Brazil). Med Care. 2011 Jun; 49(6):577-84.

23. Malo-Serrano M, Malo-Corral N. Reforma de salud en Ecuador: nunca más el derecho a la salud como un privilegio [Health reform in Ecuador: never again the right to health as a privilege]. Rev Peru Med Exp Salud Publica. 2014:31(4):754-61.

24. Eckhardt M, Carlfjord S, Faresjö T, Crespo-Burgos A, Forsberg BC, Falk M. Universal Health Coverage in Marginalized Populations: A Qualitative Evaluation of a Health Reform Implementation in Rural Ecuador. Inquiry. 2019;56:46958019880699.

25. De Paepe P, Echeverría Tapia R, Aguilar Santacruz E, Unger JP. Ecuador's silent health reform. Int J Health Serv. 2012;42(2):219 - 33. doi: 10.2190/HS. 42.2.e. PMID: 22611652.

\section{Publisher's Note}

Springer Nature remains neutral with regard to jurisdictional claims in published maps and institutional affiliations.

\section{Ready to submit your research? Choose BMC and benefit from:}

- fast, convenient online submission

- thorough peer review by experienced researchers in your field

- rapid publication on acceptance

- support for research data, including large and complex data types

- gold Open Access which fosters wider collaboration and increased citations

- maximum visibility for your research: over $100 \mathrm{M}$ website views per year

At BMC, research is always in progress.

Learn more biomedcentral.com/submissions 